\title{
Inefficiency in Cultivation of Maize on Different Sized Farm in Uttar Pradesh, India
}

\author{
A.K. Vishandass ${ }^{1}$, R.C. Lal ${ }^{2}$, Jaspal Singh ${ }^{3}$ and Amod Sharma ${ }^{*}$ \\ ${ }^{1}$ Union Public Service Commission, Dholpur House, New Delhi, India \\ ${ }^{2}$ Department of Agricultural Economics, ${ }^{3}$ Cost of Cultivation Scheme, Raja Balwant Singh \\ College, Bichpuri, Agra (Uttar Pradesh), India \\ ${ }^{4}$ Department of Agricultural Economics, Nagaland University, SASRD, Medziphema: Campus \\ (Nagaland), India \\ *Corresponding author
}

\section{A B S T R A C T}

\section{Keywords}

Uttar Pradesh, Inefficiency, Maize, Farm, Cultivation, Size

\section{Article Info}

Accepted: 07 April 2018 Available Online: 10 May 2018
It is well known fact that the globalization and ongoing reforms under WTO regime has more pressure especially being exerted on agriculture and to improve its efficiency, so as to enable agricultural commodities to compete in international market. Of late, there has been surge in demand for maize in the international market and this crop has attracted global interest. In view of this, an attempt has been made to quantify the inefficiency existing in the production process of maize and policy prescription to control inefficiencies to make Indian maize more competitive. The study reveals that various measures of inefficiency have shown an inverse relationship between farm size and inefficiency in panel - I (pre WTO) while in panel - II the medium farms were least inefficient. Unlike in panel - I, no clear relationship between farm size and inefficiency could be observed in the panel - II. Notwithstanding this, the existence of inefficiency indicates that there is a potential for decreasing cost and raising output and profit. Further, when the farms of different size-classes over two panels were considered, it was found that the degree of inefficiency of farms for respective sizes in the panel - I is significantly higher than that in the panel - II.

\section{Introduction}

Agriculture is the mainstay of Indian economy both in terms of contribution to GDP and the proportion of population dependent upon it.

A high growth rate of agriculture is essential for achieving the objective of food security at macro as well as micro levels and also for alleviating poverty level. While 21.00 per cent (at constant price) of the GDP in India is contributed by agriculture sector almost twothird of the country's population is dependent on this sector. Agriculture exports accounts for about 14.00 per cent of the country's total exports $^{14}$. 
There have been remarkable changes in Indian agriculture on account of the green revolution, which are reflected through a notable increase in use of fertilizers, agro-chemicals and pesticides. The fertilizer consumption in terms of nutrients (N, P, and $\mathrm{K}$ ) has increased from 2.21 million tones in 1970 to 1971 to more than 16.70 million tones in 2003 to 2004 and the irrigation potential has increased from 38 million hectares in 1970 to 1971 to 84.7 million hectares in 1999 to 2000.

During the period from 1970 to 1971 to 2004 to 2005 the yield of wheat has increased from 1.31 to 2.72 tonnes / hectare, rice from 1.13 to 2.03 tonnes / hectare, jowar from 0.466 to 0.841 tonnes / hectare, and maize increased from 1.28 to 1.89 tonnes / hectare.

The problem of restrained growth in agriculture sector is a cause of concern to various stakeholders. The growth rate of past may not be attainable in future unless some technological breakthrough occurs. Maintaining reasonable growth rates in output of major crops in terms of area and production is important not only for economic growth but also for sustaining food security in the country. Stepping up the growth of agriculture sector, thus, calls for priority attention.

Maize is one of the coarse cereal crops, gaining significant importance in Indian economy, contributes Rs. 6,000 crores annually to India's GDP and generates 450 million man-days of employment Globally, maize has great potential as animal feed, human food and industrial end uses, and therefore, emerged as the third most important crop after rice and wheat. Uttar Pradesh occupied about 26.00 per cent of the total maize area in the country and contributes about 22.00 per cent in the total production. Maize is a staple food for an estimated 5.00 to 6.00 per cent of the population in Uttar Pradesh $^{14}$.
Low productivity of maize in the country vis$\grave{a}$-vis other maize growing countries has remained the main concern for India. The productivity in the country is quite low with average yield being about 1.90 tonnes / ha; against 7.00 tonnes / ha in developed countries and the world average of 4.40 tonnes / ha.

Given the globalization and ongoing reforms under WTO regime, more pressure is being exerted on agriculture to improve its efficiency so as to enable agricultural commodities to complete in international market. Of late, there has been surge in demand for maize in the international market and this crop has attracted global interest. The demand pattern for food consumption is undergoing a change in India. According to results of NSSO surveys (GOI, 2003 and 2005 $\mathrm{C})$, there is a shift in the consumption pattern of the population in favour of non-cereal items like milk, vegetable, fruits, animal foods. Amongst cereals wheat and rice are more preferred. Therefore, direct human consumption of maize will either decline or remain constant in the near future. In India, during 1971 nearly 73.00 per cent of the maize grown in the country was consumed as food, which has been drastically reduced to 33.00 per cent during 2000. Whereas, the per cent of maize being used as animal feed; especially as poultry feed has increased from mere 14.00 per cent in 1971 to 47.00 per cent in 2000 . Rising income levels, lead to higher demand of meat, particularly poultry, which in turn explains such an increase in feed demand for maize.

The poultry sector is one of the fastest growing sectors in the country; the poultry industry is growing at an overall rate of 15.00 to 20.00 per cent per annum. The broiler farming which started very late in early 1970 s has picked up very fast. Similar is the case of dairy sector, as the per capita milk and milk products consumption is rising, the demand 
for maize as feed is bound to increase dramatically in future domestically.

The growth rate of area of maize crop could be seen as discouraging due to drastic decrease in its growth in the period ending 1997 to 1999 over period 1966 to 1985 mostly in all leading maize producing districts of Uttar Pradesh. Overall the limiting factors for maize farming had been articulated by labour problems, erratic rainfall, poor genotype, incidence of diseases, and low market price.

The Government of India has taken certain measures to increase production and productivity of maize. However, it is not enough to attain self-sufficiency in this area. It is also important to control inefficiencies, if any, in the production process in the competitive in the international market.

Future growth in maize sector in India will depend on two proved technologies that could boost productivity as well as contribute to lower the production cost. The productive efficiency is the central issue to all sectors of the economy and agriculture sector is no exception. Given the limited availability of resources, their judicious use will possibly accelerate generation of increased income for farmers in the agriculture sector and would also generate surplus to plough back to upgrade technology, which is expected to gear up the pace of development. It is efficiency, as a package of technical, allocative and scale and not the one obtained only in one line that can lead to generation of surplus income. It is not appropriate to infer anything about the relative efficiency of any farm simply by looking at either technical or allocative or scale efficiency. The presence of inefficiency can lead to following three major consequences.

Reduction in the quantity of output for a given set of inputs;
Under-utilization or overuse of some of inputs; and

Increase in cost of production.

Therefore, it is imperative to investigate the sources of inefficiency existing in the production process of maize and accordingly recommend policy prescription to make Indian maize competitive by controlling inefficiencies. This study was undertaken to estimate all three inefficiencies simultaneously instead of estimating one kind of inefficiency in cultivation of maize crop which has significant potential for international trade.

\section{Objectives of the study}

The specific objectives of the study were

To examine three types of inefficiencies viz. technical, allocative and scale; and

To recommend policy prescriptions required to control inefficiency and thereby making Indian maize more competitive in domestic and international markets.

\section{Hypothesis}

To test whether there will be reduction in the quantity of output for a given set of inputs when there exists inefficiency; and

Whether efficiency depends on farm-size.

\section{Sampling design and source of data}

The study is confined to the state of Uttar Pradesh due to the reason that the yield rate of maize in the state has been the lowest amongst major maize producing states. Therefore, this state has been selected purposely for an indepth analysis for deepening of understanding on efficiency of maize production in the state. The present study is based up on the data 
collected by the Uttar Pradesh center (Raja Balwant Singh College, Bichpuri, Agra) under the "Comprehensive scheme to study the cost of cultivation of principal crops in Uttar Pradesh" using cost accounting method for the period from 1993 to 1994 to 2002 to 2003. Under this Comprehensive Scheme, the design of sampling adopted was a three-stage stratified random sampling design with tehsils as the first stage unit, village / cluster as the second-stage unit and holding as the third and ultimate stage unit. The Uttar Pradesh State is demarcated into 9 homogenous agro-climatic zones and the primary sampling units (tehsils) are allocated to different zones in proportion to the total area of all crops covered in the study. The primary sampling units are selected in each zone (stratum) with probability proportional to the area under the selected crops, and with replacement. At the second stage, within each tehsil, the village / cluster was also selected following the same procedure. In each selected village / cluster all the operational holdings were enumerated and classified into 5 size-groups.

In each size class, two holdings are selected by simple random sampling, without replacement. For the present study the sample farms have been reclassified in to three size groups. Size group and year wise distribution of maize producing farms in Uttar Pradesh during the period of 1993 to 1994 to 2002 to 2003 has been presented in Table 1 .

\section{Statistical tools and techniques}

The stochastic frontier production function has been used to estimate in efficiency because the output values are bounded above by the stochastic (random) variable, $\exp \left(\mathrm{X}_{\mathrm{i}} \beta+\mathrm{v}_{\mathrm{i}}\right)$. The random error, $\mathrm{v}_{\mathrm{i}}$, can be positive or negative and so the stochastic frontier production function have been estimated by the method of MLE (maximum livelihood estimates) due to its appealing properties of consistency and invariance. A brief description of all the three inefficiency is as follows:

\section{Technical inefficiency}

Technical inefficiency reflects the inability of a farm to obtain the maximal output from a given set of inputs. A production process is said to be technically inefficient if the actual output is less than the maximum possible output from a given set of inputs. Let the production function $\mathrm{Y}$ be given by

$$
\mathrm{Y}=\mathrm{A} \prod_{\mathrm{i}-1}^{\mathrm{n}} \mathrm{X}_{1} \alpha_{\mathrm{i}} \prod_{\mathrm{k}=1}^{\mathrm{m}} \mathrm{Z}_{\mathrm{K}}{ }^{\beta}{ }_{\mathrm{k}} \exp (v)
$$

Where $\mathrm{Y}$ is output and $\mathrm{X}_{\mathrm{i}}$ and $\mathrm{Z}_{\mathrm{k}}$ are endogenous and exogenous inputs respectively. A is the efficiency parameter and $\mathrm{v}$ is while noise.

When parameter $\mathrm{A}$ is specified as

$$
\mathrm{A}=\alpha_{0} \exp (\tau) ; \quad \tau \leq 0
$$

The departure of an individual farm from the maximum output levels represented by the production frontier is reflected in $\exp (\tau)_{\text {which }}$ is defined as the technical inefficiency for each farm. If $\tau=0$, the farm remains on the production frontier and called inefficient. Since, $\tau \leq 0$, that is, $-\infty<\tau<0$, exp $(\tau)$, interpreted as technical inefficiency lies from zero and unity, implies that it varies from zero per cent to cent per cent.

Using equations (1) and (2) the production function can be written as

$$
\mathrm{Y}=\alpha_{\mathrm{o}} \prod_{\mathrm{i}-1}^{\mathrm{n}} \mathrm{X}_{\mathrm{i}} \alpha_{\mathrm{i}} \prod_{\mathrm{k}=1}^{\mathrm{m}} \mathrm{Z}_{\mathrm{K}}{ }_{\mathrm{k}}{ }_{\mathrm{k}} \exp (\tau+v)
$$

Or 


$$
\mathrm{Y}=\alpha_{\mathrm{o}} \prod_{\mathrm{i}-1}^{\mathrm{n}} \mathrm{X}_{\mathrm{i}} \alpha_{\mathrm{i}} \prod_{\mathrm{k}=1}^{\mathrm{m}} \mathrm{Z}_{\mathrm{K}}{ }^{\beta}{ }_{\mathrm{k}} \exp (\varepsilon)
$$

Where, $\varepsilon=\tau+\mathrm{v}$

The random variable $\mathrm{v}$ stands for white noise that is beyond the control of the farms and can affect production favourably and unfovourably. That is, $\tau \leq 0$. If the farm is technically efficient, $\tau=0$, then the production frontier that gives the maximum possible output is given by

$$
\mathrm{Y}=\alpha_{\mathrm{o}} \prod_{\mathrm{i}-1}^{\mathrm{n}} \mathrm{X}_{\mathrm{i}} \alpha_{\mathrm{i}} \prod_{\mathrm{k}=1}^{\mathrm{m}} \mathrm{Z}_{\mathrm{K}}{ }^{\beta}{ }_{\mathrm{k}} \exp (\mathrm{v})
$$

If a farm is technically inefficient, it would incur more cost than necessary for producing a given quantity of output. The extra cost of producing below the production frontier or above the cost function due to technical inefficiency.

\section{Allocative inefficiency}

Allocative inefficiency reflects the inability of a farm to use inputs in optimal proportion, given their respective price and technology. A farm is said to be allocatively inefficient if the produces at any point off the least cost expansion path. This condition is attained when ratios of the marginal products are not equal to the ratios of input-prices.

Thus the allocative inefficiency is introduced by the condition when

$$
\frac{M P_{j}}{M P_{i}} \neq \frac{W_{j}}{W_{i}} \exp \left(u_{j}\right), j=1,2,3, \ldots \ldots ., n(6)
$$

Where,

$\mathrm{u}_{\mathrm{j}}=$ allocative inefficiency random variable $\mathrm{MP}_{\mathrm{j}}=$ the marginal product of the $\mathrm{j}^{\text {th }}$ input. $\mathrm{W}=$ the price of $\mathrm{j}^{\text {th }}$ input
If the $u_{j}=0$, the farm is allocatively efficient. On the other hand, if $\mathrm{u}_{\mathrm{j}}>0$ or $\mathrm{u}_{\mathrm{j}}<0$ for same $\mathrm{j}$, the input $\mathrm{X}_{\mathrm{j}}$ is under utilized or over utilized respectively at given $\mathrm{W}_{\mathrm{j}}$ and $\mathrm{W}_{\mathrm{i}}$.

\section{Scale inefficiency}

The concept of scale inefficiency is relevant in the context of right choice of quantity of output produced. A farm said to be scale efficient if it produces at the point where marginal cost is equal to the price of output, in other words farm's production is set at the optimal level. If a farm produces at the suboptimal level, producing output at a level which is either smaller or greater than the one that corresponds to profit maximization, is said to be scale inefficient. The scale inefficiency is introduced in the following way:

$\frac{\partial \mathrm{C}}{\partial \mathrm{Y}}=\mathrm{P} \quad \exp (\xi)$

Where,

$\mathrm{C}=$ total variable cost.

$\xi=$ scale inefficiency parameter

Given P (the production plan) is optimal if the scale inefficiency parameter $\xi$ is zero. On the other hand, if $\xi>0(<0)$, the actual output is greater (less) than the optimal level of output.

\section{Measures of inefficiency}

Inefficiency can cause loss in output, increase in cost and/ or loss in profit. To quantify level of inefficiency, seven measures viz. LOTI (Loss in Output from the Frontier level due to Technical Inefficiency), ICTI (Increase in Cost above the Frontier level due to Technical Inefficiency), ICAI (Increase in Cost above the Frontier level due to Allocative Inefficiency), ICTAI (Increase in Cost above 
the Frontier level due to Technical and Allocative Inefficiency), ICTASI (Increase in Cost above the Frontier level due to Technical, Allocative and Scale Inefficiency), LPSI (Loss in Profit from the Frontier level due to Scale Inefficiency) and LPTASI (Loss in Profit from the Frontier level due to Technical, Allocative and Scale Inefficiency) have been developed. Econometrics formulations of the various Measures developed to quantify level of inefficiency are given in Appendix - I

\section{Inefficiency by farm-size}

The LOTI shows (Table 2) that the small, medium and large farms are inefficient by 15.47 per cent, 12.67 per cent and 12.43 per cent respectively in the panel - I. Similarly, other measures of inefficiency namely ICTI, ICAI, ICTAI, LPSI, LPTASI and ICTASI have revealed that large farms are least inefficient, followed by medium farms. Small farms lag behind in terms of efficiency in this panel. Thus, an inverse relationship between farm size and inefficiency exists in panel - I.

In the panel - II, various measures of inefficiency have shown that the medium farms are least inefficient. Unlike in panel - I, no clear relationship between farm size and inefficiency could be observed in the panel II. Notwithstanding this, the existence of inefficiency indicates that there is a potential for decreasing cost and raising output and profit.

In panel - I, while the elasticity of both human and bullock labour and also of land have inverse relationship with the farm-size, the elasticity of fertilizer is directly related with farm-size. Inverse relationship between the coefficient of land and farm size shows that small farms tend to take better care of their farms. The growth rate of output has also exhibited a negative relationship with the farm-size. The average growth of all farms has been moderate at 4.7 per cent during the period from 1993 to 1994 to 1997 to 1998.

As in panel - I, elasticity of human labour and also land has exhibited an inverse relationship with the farm-size in panel - II. However, bullock labour has been found to dominate in medium farms. Inverse relationship between the coefficient of land and farm-size shows that small farms tend to take better care of their farms. The elasticity of fertiliser and farm-size has shown a direct relationship. No clear relationship between the seed elasticity and the size of the farms has emerged in panel - II. The growth rate of output has also exhibited negative relationship with the farmsize. The average growth of all farms has been high at 7.0 per cent in panel - II viz., the period from 1998 to 1999 to 2002 to 2003.

Further, when the farms of different sizeclasses over two panels are considered, it is found that the degree of inefficiency of farms for respective sizes in the panel - I is significantly higher than that in the panel - II.

\section{Measures to reduce inefficiencies}

Inefficiency has existed over time across farms of various sizes. This adversely affects not only cost and profitability but also competitiveness of the farm produce. To reduce inefficiency and also enhance competitiveness of maize, following policy measures have been prescribed:

\section{Remunerative price policy}

The instrument of remunerative or Minimum Support prices (MSP) envisages applicability of the benefits under the Scheme across the board. However, it has been observed that the existing system of price support operations has remained concentrated in a few pockets of the State while it has not been effective in several other districts. Thus, benefits of MSP Scheme 
have bypassed a large cross section of farmers. Therefore, procurement should not be concentrated in a few selected pockets alone but it should be broad based to make price support operations more effective in all parts of the state.

\section{Agriculture credit}

Credit enables a farmer to extend his control over ownership of resources. In a liberalized trade scenario, the need for credit to meet technology requirements is quiet high. It has, however, been observed that limits to sanction credit for activities such as investment in land development and ground water is low which results in mismatch between credit availability and requirement, making the agriculture sector less competitive in the global market. As there is considerable unmet demand for agriculture credit, it is recommended that credit flow should be substantially enhanced at low rate of interest for agriculturists in general.

\section{Risk management}

Agriculture is an 'industry' under open sky where risk of aberrant weather conditions is quite high. Farmers in the State of Uttar Pradesh are generally resource poor, have low propensity to absorb losses and therefore they need to be protected against risk. For this purpose, risk management strategies such as 'Contract Farming' and 'Commodity Exchanges' as a tool for farm support should be adopted on a wider scale.

Farmers in the State are not in a position to invest in land improvement and modem inputs because of constraint of financial resources. Contract farming can fill up this gap by providing them with quality inputs, technical guidance and management skills. From the standpoint of corporate bodies, contract farming reduces the supply risk, while the farmers enter into contractual arrangements with companies in order to minimize price risks.

The basic function of a commodity exchange is efficient price discovery, which is enabled by the interaction of numerous buyers and sellers. The major problem for farmers is uncertainty of income or prices due to limited knowledge of prices besides the dependency on the monsoon. Commodity exchanges help to fill this void. It is recommended that the extension of commodity exchanges should be promoted in various parts of the country.

\section{Agriculture marketing}

The Agriculture marketing system, which facilitates transferring the farm products from farms to the consumers and farm inputs from manufacturers to the farmers, is characterized by pervasive government intervention. State APMC Act governs promotions of agriculture markets in private/ cooperative sector.

The state government should plough back market fees for market development, hold regular elections of market committees and create cleaning, sorting, grading and packaging facilities in villages and allow traders to buy in the villages by declaring these places as sub-yards.

Rural Uttar Pradesh is electronically unconnected, though country's software achievements are remarkable. To enable both the producers and the sellers to have access to information on day-to-day prices, IT in agricultural marketing must bloom in the fields for a wider spatial coverage to generate useful database to enable farmers to take right decision at right time.

This will go a long way in preventing distress sale and would increase profitability and efficiency. 


\section{Infrastructure}

Infrastructure such as construction of roads, provision of goods carriage, storage facilities in the villages have been inadequate, primitive and inefficient which result in loss of output and pro it of farmers. Therefore, arrangements for adequate storage facilities in the rural area and at market level have been recommended for reducing the loss in profit from the sale of their output. Further, co-operative marketing societies, if formed, will enable farms, especially small and medium ones, not to sell their output in the local markets where sale price is low. Therefore, co-operative marketing societies for sale of produce in mandis should be popularized for the benefits of the farmers. As infrastructure facilities require substantial capital investment, intervention of government to create such infrastructure facilities is called for.

\section{Education, research and training}

Farms of various sizes have been found to over utilise different inputs. Inappropriate input combination or lack of precision farming is the consequence of lack of education and knowledge amongst farmers, which increases the cost. Therefore, farmers should be trained to adopt scientific method of cultivation and precision farming to enable them to rationally utilise the inputs keeping in mind their technical efficacy, costs, appropriate timing of sowing, spraying insecticides, harvesting etc.

This would also help them to obtain higher yield level at low cost. Further, emphasis needs to be laid on transfer of research from 'laboratories to land'. It is expected that the cost of inefficiency will decrease with higher investment in dissemination of information, education, research and training.

It is high time to move to a dynamic production and trading of maize. If policies are properly implemented, the degree of inefficiency will be considerably reduced, if not eliminated. The policies for enhancing efficiencies and thus competitiveness of maize should be implemented with a sense of urgency.

Table.1 Size group and year wise distribution of maize producing farms in Uttar Pradesh during the period of 1993-94 to 2002-03 (Per cent)

\begin{tabular}{|c|c|c|c|c|c|}
\hline Panel & Year & Small & Medium & Large & Total \\
\hline \multirow[t]{5}{*}{ Panel - I } & 1993-94 & 32.71 & 47.66 & 19.63 & $100(107)$ \\
\hline & 1994-95 & 35.86 & 43.45 & 20.69 & $100(145)$ \\
\hline & 1995-96 & 32.35 & 45.88 & 21.76 & $100(170)$ \\
\hline & 1996-97 & 32.36 & 44.09 & 23.66 & $100(186)$ \\
\hline & $1997-98$ & 35.68 & 42.72 & 21.60 & $100(213)$ \\
\hline \multirow[t]{5}{*}{ Panel - II } & 1998-99 & 35.40 & 42.86 & 21.74 & $100(161)$ \\
\hline & 1999-00 & 34.83 & 40.45 & 24.72 & $100(89)$ \\
\hline & 2000-01 & 36.36 & 39.09 & 24.55 & $100(111)$ \\
\hline & 2001-02 & 36.57 & 42.54 & 20.90 & $100(134)$ \\
\hline & 2002-03 & 34.07 & 47.25 & 18.68 & $100(91)$ \\
\hline
\end{tabular}

(Figures in parentheses indicate number of sample farmers growing maize) 
Table.2 Inefficiency in maize producing farms of different farm size groups in Uttar Pradesh during 1993-94 to 2002-03

\begin{tabular}{|l|c|c|c|c|c|c|c|c|}
\hline $\begin{array}{l}\text { Measures of } \\
\text { inefficiency }\end{array}$ & \multicolumn{3}{|c|}{ Panel - I (1993-94 to 1997-98) } & \multicolumn{3}{|c|}{ Panel - II (1998-99 to 2002-03) } \\
& Small & Medium & Large & $\begin{array}{c}\text { All } \\
\text { farms }\end{array}$ & Small & Medium & Large & $\begin{array}{c}\text { All } \\
\text { farms }\end{array}$ \\
\hline LOTI & 15.47 & 12.67 & 12.43 & 14.49 & 7.90 & 7.64 & 7.68 & 7.81 \\
\hline ICTI & 28.97 & 28.17 & 26.36 & 27.30 & 12.82 & 14.20 & 17.96 & 14.76 \\
\hline ACAI & 41.64 & 38.41 & 33.50 & 40.20 & 29.33 & 26.85 & 35.25 & 31.96 \\
\hline ACTAI & 82.67 & 74.00 & 71.10 & 79.09 & 45.91 & 44.87 & 59.53 & 54.64 \\
\hline LPSI & 28.96 & 24.46 & 23.78 & 24.57 & 19.18 & 18.15 & 17.28 & 18.73 \\
\hline LPTASI & 76.65 & 64.64 & 61.71 & 68.09 & 64.09 & 52.91 & 46.58 & 49.17 \\
\hline ICTASI & 91.78 & 80.29 & 76.76 & $\mathbf{8 3 . 6 0}$ & $\mathbf{6 8 . 1 8}$ & $\mathbf{5 2 . 3 3}$ & $\mathbf{7 2 . 8 0}$ & $\mathbf{6 7 . 5 9}$ \\
\hline
\end{tabular}

\section{Appendix I}

Measures developed to quantify level of inefficiency and their econometrics formulations are as follows:

\section{LOTI (Loss in output due to Technical inefficiency)}

LOTI measures the loss in output from the frontier level due to technical in efficiency only. The equation (3) can be re-written in log form as follows

$$
\ln \mathrm{Y}=\gamma+\sum_{\mathrm{i}=1}^{\mathrm{n}} \alpha_{\mathrm{i}} \ln \mathrm{X}_{\mathrm{i}}+\sum_{\mathrm{k}=1}^{\mathrm{m}} \beta_{\mathrm{k}} \ln \mathrm{Z}_{\mathrm{k}+}(\tau+\mathrm{v})
$$

Where $\gamma=\ln \alpha_{0}$

Since, $\tau<0$,

$\ln \mathrm{Y}=\gamma+\sum_{\mathrm{i}=1}^{\mathrm{n}} \alpha_{\mathrm{i}} \ln \mathrm{X}_{\mathrm{i}}+\sum_{\mathrm{k}=1}^{\mathrm{m}} \beta_{\mathrm{k}} \ln \mathrm{Z}_{\mathrm{k}}+\mathrm{v}$

Thus $\ln \mathrm{Y}$ is bounded from above by the stochastic production frontier with technical inefficiency relative to the frontier given by $\tau$ $=0$, then the production frontier that gives the maximum possible output is given by

$$
\mathrm{Y}=\alpha_{\mathrm{o}} \prod_{\mathrm{i}-1}^{\mathrm{n}} \mathrm{X}_{\mathrm{i}} \alpha_{\mathrm{i}} \prod_{\mathrm{k}=1}^{\mathrm{m}} \mathrm{Zi}{ }^{\beta_{\mathrm{k}}} \exp (\mathrm{v})
$$

Thus,

LOTI $=\frac{(10)-(3)}{(10)}=1-\exp (\tau)$

\section{ICTI (Increase in cost due to technical inefficiency)}

ICTI measures increase in the cost above the frontier (minimum) level due to technical inefficiency only. For developing this measure, implication of a farm operating below the cost frontier is being derived

The total variable cost of the farm is

$$
\mathrm{C}=\mathrm{W}^{1} \mathrm{X}=\sum_{\mathrm{i}-1}^{\mathrm{n}} \mathrm{W}_{\mathrm{i}} \mathrm{X}_{\mathrm{i}}
$$

Where $\mathrm{W}_{\mathrm{i}}$ is the price of $\mathrm{X}_{\mathrm{i}}$ and $\mathrm{r}=\Sigma \alpha_{\mathrm{i}}$

$$
\begin{aligned}
& =\sum_{\mathrm{i}=1}^{\mathrm{n}} \mathrm{W}_{\mathrm{i}}\left\{\mathrm{k}_{\mathrm{i}} \mathrm{Y}^{1 / \mathrm{r}}\left[\prod_{\mathrm{i} \neq 1}^{\mathrm{m}} \frac{\left(\mathrm{Wi}^{\mathrm{a}}{ }^{\mathrm{i} / \mathrm{r}}\right)}{\mathrm{W}_{\mathrm{i}}}\right]\left(\prod_{\mathrm{k}-1}^{\mathrm{m}} \mathrm{Z}_{\mathrm{k}}-^{\beta}{ }^{k}\right) \exp [-(1 / \mathrm{r})(\tau+\mathrm{v})]\right. \\
& =\mathrm{kY}^{1 / \mathrm{r}}\left(\prod_{\mathrm{i}=1}^{\mathrm{n}} \mathrm{Wi} \mathrm{i}^{{ }^{\mathrm{i} / \mathrm{r}}}\right)\left(\prod_{\mathrm{k}-1}^{\mathrm{m}} \mathrm{Z}_{\mathrm{k}}{ }^{-\beta} \mathrm{k}^{k}\right) \exp [-(1 / \mathrm{r})(\tau+\mathrm{v})]
\end{aligned}
$$




$$
\begin{aligned}
& \text { Or, } \\
& \ln \mathrm{C}=\ln \mathrm{k}+(1 / \mathrm{r}) \ln Y+\sum_{\mathrm{i}=1}^{\mathrm{n}} \alpha_{\mathrm{i}} \mathrm{r}-\ln \mathrm{W}_{\mathrm{i}}-\sum_{\mathrm{k}=1}^{\mathrm{m}} \mathrm{k}_{\mathrm{k} / \mathrm{r}} \ln Z_{k}-(1 / \mathrm{r})(\tau+\mathrm{v})
\end{aligned}
$$

Where,

$$
\begin{aligned}
& \mathrm{k}=\ln \left(\sum_{\mathrm{i}=1}^{\mathrm{n}} \mathrm{k}_{\mathrm{i}}\right) \\
& =\ln \left[\sum_{\mathrm{i}=1}^{\mathrm{n}} \alpha_{\mathrm{i}} \alpha_{0}^{-1 / t}\left(\prod_{\mathrm{i}=1}^{\mathrm{n}} \alpha_{\mathrm{i}}^{\alpha_{\mathrm{i}}}\right)^{(-1 / \mathrm{r})}\right] \\
& =\ln \left[\left(\sum_{\mathrm{i}=1}^{\mathrm{n}} \alpha_{\mathrm{i}}\right)\left(\alpha_{0}\left(\prod_{\mathrm{i}=1}^{\mathrm{n}} \alpha_{\mathrm{i}}^{\alpha_{\mathrm{i}}}\right)^{(-1 / \mathrm{r})}\right]\right. \\
& =\ln \mathrm{r}-\ln \alpha_{0}-(1 / \mathrm{r}) \ln \left(\prod_{\mathrm{i}=1}^{\mathrm{n}} \alpha_{\mathrm{i}}^{\alpha_{\mathrm{i}}}\right)
\end{aligned}
$$

Since $\tau<0$, equation (13) shows that

$\ln C_{>} \quad \ln \quad \mathrm{k}+\quad(1 / \mathrm{r})$
$\sum_{\mathrm{Y}+1}^{n}\left(\alpha_{i} / r\right) \ln W_{i}-\sum_{k=1}^{m}\left(\beta_{k} / r\right) \ln Z_{k}-v / r$

That is, the cost function is bounded from below. If the farm is technically efficient, that is $\tau=0$, the best practice cost frontier is,

$\mathrm{C}={ }^{\mathrm{k} Y^{1 / \mathrm{r}}}\left[\prod_{\mathrm{i}=1}^{\mathrm{n}}\left(\mathrm{Wi}^{\alpha^{\mathrm{i} / \mathrm{r}}}\right)\right]+\ln \left(\prod_{\mathrm{k}-1}^{\mathrm{m}} \mathrm{Z}_{\mathrm{k}}{ }^{-\beta_{\mathrm{k}}{ }^{k}}\right) \exp (-\mathrm{v} / \mathrm{r})$

Therefore, the increase in cost due to technical inefficiency is,

$$
\mathrm{ITCI}=\frac{(12)-915)}{(15)}=\exp (-\tau / \mathrm{r})-1
$$

ICTAI (increase in cost due to technical and allocative inefficiency)

ICTAI measures increase in the cost above the frontier level due to simultaneous presence of technical and allocative inefficiencies.

The input demand function and the cost function (Adhikari, 1999) are given by equation (18) and (19) respectively.

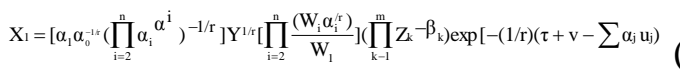

$$
\begin{aligned}
& \mathrm{W}_{\mathrm{j}} \mathrm{X}_{\mathrm{j}}=\frac{\alpha_{\mathrm{i}} \mathrm{W}_{1} \mathrm{X}_{1}}{\alpha_{1}} \exp \left(-\mathrm{u}_{\mathrm{j}}\right) ; j \mathrm{j}=2,3, \ldots \ldots \mathrm{n}
\end{aligned}
$$

Summing all $\mathrm{j}=2,3, \ldots \ldots \mathrm{n}$

It would be

$$
\sum_{j=2}^{n} W_{j} X_{j}=\frac{W_{1} X_{1}}{\alpha_{1}}\left[\alpha_{1}+\sum_{j=2}^{n} \alpha_{j} \exp \left(-u_{j}\right)\right]-W_{1} X_{1}
$$

Hence,

$$
\begin{aligned}
& \mathrm{C}=\mathrm{W}_{1} \mathrm{X}_{1}+\sum_{\mathrm{j}=2}^{\mathrm{n}} \mathrm{W}_{\mathrm{j}} \mathrm{X}_{\mathrm{j}} \\
& =\sum_{\mathrm{j}=1}^{\mathrm{n}} \mathrm{W}_{\mathrm{j}} \mathrm{X}_{\mathrm{j}} \\
& =\frac{\mathrm{W}_{1} \mathrm{X}_{1}}{\alpha_{1}}\left[\alpha_{\mathrm{j}} \exp \left(-\mathrm{u}_{\mathrm{j}}\right)\right]
\end{aligned}
$$

Putting the value of $\mathrm{X}_{1}$ from (18) in to (20), the equation will be,

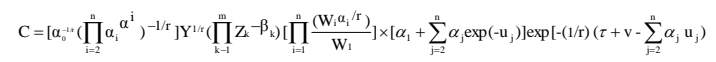

Consider

$\mathrm{K}=\ln \left(\sum_{\mathrm{i}=1}^{\mathrm{n}} \mathrm{k}_{\mathrm{i}}\right)=\ln \mathrm{r}-1 / \mathrm{r} \ln \alpha_{0}-1 / \mathrm{r} \ln \left(\prod_{\mathrm{i}=1}^{\mathrm{n}} \Sigma \alpha_{\mathrm{i}}^{\alpha \mathrm{i}}\right)$

$\mathrm{K}=\ln \mathrm{r}=\ln \alpha_{0}{ }^{(-1 / \mathrm{r})}\left[\left(\prod_{\mathrm{i}=1}^{\mathrm{n}} \alpha_{\mathrm{i}}^{\alpha \mathrm{i}}\right)^{-1 / \mathrm{r}}\right]$ 
$e_{0}{ }^{-1 / r}\left(\prod_{i=1}^{n} \alpha_{i}{ }^{\alpha i}\right)^{-1 / r}-\exp (k-\ln r)$

Hence, from (21), it can be written as

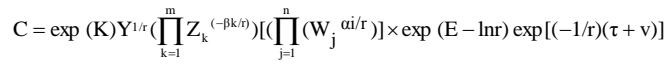

Where,

$E=\ln \left[\alpha_{1}+\sum_{j=2}^{n} \alpha_{j} \exp \left(-u_{j}\right)\right]+1 / r \sum_{j=2}^{n} \alpha_{j} u_{j}$

If $\mathrm{u}_{2}=\mathrm{u}_{3 \ldots \ldots \ldots} \mathrm{u}_{\mathrm{n}}=0$, then

$E=\ln \left[\alpha_{1}+\sum_{j=2}^{n} \alpha_{j} \exp \left(-u_{j}\right)\right]+1 / r \sum_{j=2}^{n} \alpha_{j} u_{j}$

In $\log$-linear form, the cost function i.e. equation (22) can be re-written as

$\left.\ln \mathrm{C}=\mathrm{K}-\left(\prod_{\mathrm{k}=1}^{\mathrm{m}}-\beta \mathrm{k} / \mathrm{r}\right) \ln \mathrm{Z}_{\mathrm{k}}\right)+1 / \mathrm{r} \ln \mathrm{Y}+\left(\prod_{\mathrm{j}=1}^{\mathrm{n}}\left(\alpha_{\mathrm{j}} / \mathrm{r} \ln \mathrm{W}_{\mathrm{j}}\right)-1 / \mathrm{r}(\tau+\mathrm{v})+(\mathrm{E}-\ln \mathrm{r})\right.$

Hence,

$\left.\ln \mathrm{C}>\mathrm{K}-\left(\prod_{\mathrm{k}=1}^{\mathrm{m}}-\beta \mathrm{k} / \mathrm{r}\right) \ln \mathrm{Z}_{\mathrm{k}}\right)+1 / \mathrm{r} \ln \mathrm{Y}+\left(\prod_{\mathrm{j}=1}^{\mathrm{n}}\left(\alpha_{\mathrm{j}} / \mathrm{r} \ln \mathrm{W}_{\mathrm{j}}\right)-\mathrm{v} / \mathrm{r}\right.$

Thus, the cost function is bounded from below (in logarithmic term) by the stochastic frontier (given by the right hand side of (25). If the farm both technically and allocatively efficient, that is, $\tau=0$ and $\mathrm{u}_{\mathrm{j}}=0$, then from (25) we have,

$$
\mathrm{C}=\exp (\mathrm{K}) \mathrm{Y}^{1 / \mathrm{r}}\left(\prod_{\mathrm{k}=1}^{\mathrm{m}}-\beta_{\mathrm{k}} / \mathrm{r}\right)\left[\left(\prod_{\mathrm{j}=1}^{\mathrm{n}}\left(\alpha_{\mathrm{j}}^{/ \mathrm{r}}\right)\right] \exp (-\mathrm{v} / \mathrm{r})\right.
$$

(It is noted that $\tau=0$ and $\mathrm{E}=\ln \mathrm{r}$ )

Therefore, the increase in cost due to both technical and allocative inefficiency or the cost of both technical and allocative in efficiency is
$\mathrm{ICTAI}=\frac{(22)-(27)}{(27)}=\exp [\mathrm{E}-\ln \mathrm{r}-\tau / \mathrm{r}]-1$

\section{ICAI (Increase in cost due to allocative inefficiency)}

ICAI measures increase in cost above the frontier (minimum) level due to allocative inefficiency only.

If the farm is technically efficient but allocatively inefficient, that is $\tau=0$ but $\mathrm{u}_{\mathrm{j}} \neq 0$, the increase in cost due to allocative inefficiency or the cost of allocative inefficiency can be derived by putting $\tau=0$ in equation (28)

$\mathrm{ICAI}=\exp (\mathrm{E}-\ln \mathrm{r})-1(29)$

It is noted that the above measure has been derived on an implicit assumption that there is no tendency to systematically over utilize or under-utilized any input relative to any other input.

ICTASI (Increase in cost due to technical, allocative and scale inefficiency)

From equations (7) and (22), we get

$$
\frac{\partial \mathbf{C}}{\partial \mathbf{Y}}=\frac{\mathbf{C}}{(\mathbf{r} \times \mathbf{Y})}=\mathbf{P} \exp (\xi)
$$

In logarithmic form

$\ln \mathrm{C}=\ln \mathrm{r}+\ln \mathrm{P}+\xi$

From (22), we get

$\ln \mathrm{Y}=-\mathrm{rK}+\mathrm{r} \ln \mathrm{C}+\sum_{\mathrm{k}=1}^{\mathrm{m}} \beta_{\mathrm{k}} \ln \mathrm{Z}_{\mathrm{k}}-\sum_{\mathrm{i}=1}^{\mathrm{n}} \alpha_{\mathrm{j}} \ln \mathrm{W}_{\mathrm{j}}(\tau+\mathrm{v})-\mathrm{r}(\mathrm{E}-\ln \mathrm{r})$

Substituting (32) in (31), we get

$\mathrm{C}=\exp \{-\mathrm{rK} /(1-\mathrm{r})\}\left(\prod_{\mathrm{k}=1}^{\mathrm{m}} \mathrm{Z}_{\mathrm{k}} \beta_{\mathrm{k}}{ }^{/(\mathrm{i}-\mathrm{R})}\right)\left(\prod_{\mathrm{i}=1}^{\mathrm{n}}\left(\mathrm{W}_{\mathrm{i}} \alpha_{\mathrm{i}}^{/(1-\mathrm{r})}\right)\left(\mathrm{P}^{1 /(1-\mathrm{r})}\right)\right.$

$\times \exp [(1 /(1-\mathrm{r})\{(\tau+\mathrm{v})-\mathrm{r}(\mathrm{E}-\ln \mathrm{r})+(\xi+\ln r)$ 
If the farm is technically, allocatively and scale efficient, that is $\tau=0, \mathrm{u}_{\mathrm{j}}=0$ (i.e. $\mathrm{E}=\ln$ r) and $\xi=0$, then the stochastic cost frontier is

$\mathrm{C}=\exp \{-\mathrm{rK} /(1-\mathrm{r})\} \exp \left(\prod_{\mathrm{k}=1}^{\mathrm{m}} \mathrm{Z}_{\mathrm{k}} \beta_{\mathrm{k}}{ }^{(\mathrm{i}-\mathrm{R})}\right) \exp \left(\prod_{\mathrm{i}=1}^{\mathrm{n}}\left(\mathrm{W}_{\mathrm{i}} \boldsymbol{\alpha}_{\mathrm{i}}^{(1-\mathrm{r})}\right)\left(\mathrm{P}^{1 /(1-\mathrm{l})}\right)\right.$

Obviously, (34) < (33)

The increase in cost due to technical, allocative and scale inefficient or the cost of technical, allocative and scale inefficiency (that is, $\tau \neq 0, u_{j} \neq 0$, (i.e. $E \neq \ln r$ ) and $\xi \neq 0$,) is

$\operatorname{ICTASI}=\frac{(31)-(32)}{(32)}=\exp [1 /(1-\mathrm{r})\{\tau-\mathrm{r}(\mathrm{E}-\ln \mathrm{r})+\xi\}]-1$

LPTASI (Loss in profit due to technical, allocative and scale inefficiency)

From equation (22) and (31) we get production frontier in logarithm terms

$\ln Y=-r K /(1-r)+1 /(1-r)\left(\sum_{k=1}^{m} \beta_{k} \ln Z_{k}\right)-1 /(1-r)\left(\sum_{i=1}^{n} \alpha_{i} \ln \alpha_{i}\right)-r /(1-r) \ln P$

$\mathrm{Y}=\exp \left[\{-\mathrm{rK} /(1-\mathrm{r})\} \exp \left\{\prod_{\mathrm{k}=1}^{\mathrm{m}} \mathrm{Z}_{\mathrm{k}}{\beta_{\mathrm{k}}}^{\prime(\mathrm{i}-\mathrm{r})}\right\}\left\{\prod_{\mathrm{i}=1}^{\mathrm{n}}\left(\mathrm{W}_{\mathrm{i}} \alpha_{\mathrm{i}}^{(1-\mathrm{r})}\right\}\left\{\mathrm{P} \mathrm{P}^{1 /(1-\mathrm{r})}\right\}\right]\right.$

$\times \exp [(1 /(1-r)\{(\tau+v)-r(E-\ln r)+r(\xi+\ln r)\}]$

Where,

$K=1 / r\left(\ln \alpha_{0}+r \ln r+\sum_{i=1}^{n} \alpha_{i} \ln \alpha_{i}\right)$

If the farm is technically, allocatively and scale efficient (that is, $\tau=0, \mathrm{u}_{\mathrm{j}}=0$, (i.e. $\mathrm{E}=\ln$ r) and $\xi=0$ ), then the stochastic production frontier is

$\mathrm{Y}=\exp \left[\{-\mathrm{rK} /(1-\mathrm{r})\}\left\{\prod_{\mathrm{k}=1}^{\mathrm{m}} \mathrm{Z}_{\mathrm{k}}{\beta_{\mathrm{k}}}{ }^{(\mathrm{i}-\mathrm{r})}\right\}\left\{\prod_{\mathrm{i}=1}^{\mathrm{n}}\left(\mathrm{W}_{\mathrm{i}}-\alpha_{\mathrm{i}}^{\prime(1-\mathrm{r})}\right\}\left\{\mathrm{P}{ }^{\mathrm{I} /(\mathrm{l}-\mathrm{r})}\right\}\right] \times \exp \{\mathrm{v} /(1-\mathrm{r})\}\right.$

Obviously (38)> (37)

Now, profit $\Pi$ is defined as,

$\Pi=\mathrm{PY}-\mathrm{C}$

On subtracting (38) and (33), we get

$\Pi=\exp \{-\mathrm{rK} /(1-\mathrm{r})\}\left(\prod_{\mathrm{k}=1}^{\mathrm{m}} \mathrm{Z}_{\mathrm{k}} \beta_{\mathrm{k}} /(\mathrm{i}-\mathrm{r})\right)\left(\prod_{\mathrm{i}=1}^{\mathrm{n}}\left(\mathrm{W}_{\mathrm{i}}-\alpha_{\mathrm{i}}^{/(1-\mathrm{r})}\right)\left(\mathrm{P}^{1 /(1-\mathrm{r})}\right)\right.$
$\times \exp [(1 /(1-\mathrm{r})\{(\tau+\mathrm{v})-\mathrm{r}(\mathrm{E}-\ln \mathrm{r})+(\xi+\ln \mathrm{r})]\{(1-\mathrm{r} \exp (\xi)]$

If the farm technically, allocatively and scale efficient (that is, $\tau=0, u_{j}=0$, (i.e. $E=\ln r$ ) and $\xi=0$ ), then the stochastic production frontier is

$$
\begin{aligned}
& \Pi=\exp \{-\mathrm{rK} /(1-\mathrm{r})\}\left(\prod_{\mathrm{k}=1}^{\mathrm{m}} \mathrm{Z}_{\mathrm{k}} \beta_{\mathrm{k}}{ }^{/(\mathrm{i}-\mathrm{r})}\right)\left(\prod_{\mathrm{i}=1}^{\mathrm{n}}\left(\mathrm{W}_{\mathrm{i}}-\alpha_{\mathrm{i}}^{/(1-\mathrm{r})}\right)\left(\mathrm{P}^{1 /(1-\mathrm{r})}\right)\right. \\
& \times \exp [(1 /(1-\mathrm{r})(\mathrm{v}+\mathrm{ln} \mathrm{r})](1 / \mathrm{r}-1)
\end{aligned}
$$

Obviously, (39) < (40)

If the farm technically, allocatively and scale efficient (that is, if $\tau \neq 0, u_{j} \neq 0$, (i.e. $E \neq \ln r$ ) and $\xi \neq 0$ ), then loss in profit due to technical, allocative and scale inefficient is given by

$$
\begin{aligned}
& \text { LPTASI }=\frac{(40)-(39)}{(40)} \\
& =1-\exp [1 /(1-r)(\tau-r(E-\ln r)+\xi)][(1-r) \exp (\xi)
\end{aligned}
$$

$=1-[(1-\operatorname{rexp}(\xi \exp (-\mathrm{r})] \exp (\xi)] \exp [1 /(1-\mathrm{r})(\tau-\mathrm{r}(\mathrm{E}-\ln \mathrm{r})+\mathrm{r} \xi \xi)$

\section{LPSI (Loss in profit due to scale inefficiency)}

LPSI measures the loss in profit for producing output below the profit frontier due to scale inefficiency only. This measure is explicitly based on the assumption that the farm is technically and allocatively efficient.

If the farm is technically and allocatively efficient but scale inefficient, that is to say that if $\tau=0, u_{j}=0$ (i.e. $E=\ln r$ ) but $\xi \neq 0$, the loss in profit due to scale inefficiency is

LPSI $=1-[\{1-\mathrm{r} \exp (\xi \xi /(1-\mathrm{r})] \exp (\mathrm{r} \xi)$ 


\section{References}

Aquino, AP., Maruyama, A. and Kikuchi, M. 2001. Japanese Journal of Tropical Agriculture. 43(4): 277-284.

Bach, E., Kikun, E and John C. 2002. Agrekon. Journal for Farming Systems Research. 2(2): 91-108.

Borthakur, N. and Krishnamoorthy, S. 2002. Inter-Zonal Efficiency in Rice Production in Assam: A Frontier Production Function Approach. Rural Development: Constraints \& Opportunities. Agricultural Economics Research Review. (Conference proceeding).

Elsamma, J. and George, MV. 2002. Technical efficiency in Rice production - A frontier production function approach. Agricultural Economics Research Review. 15(1): 50-55.

Greens, WH. 1993. The Econometric Approach to Efficiency Analysis. The Measurement of Productive Efficiency Techniques and Applications. Oxford University Press.

Kumbhakar, SC. and Bhattacharyya, A. 1992. Price Distortion and Resource - use Efficiency in Indian Agriculture: A Restricted Profit Function Approach. Review of Economics and Statistics. LXXIV (2). May: 231-239.
Maruyama, A., Hans, P. and Singh, B. 2001. Japanese Journal of Tropical Agriculture. 43(4): 277-284.

Parsalaw, W. and Harvey, C. 1996. Constraints on The Success Of Structural Adjustment Programmes in Africa. Macmillan Press Ltd. Basingstoke, UK : 76-99.

Seyoum, ET., Battese, GE. and Fleming, EM. 1998. Technical Efficiency and Productivity of Maize Producers in Eastern Ethiopia: A Study of Farmers within and Outside the Sasakawa Global 2000 Project. Journal of Agricultural Economics. 19(3): 341348.

Tripp, R. 1993. World Development, Oxford. 21(12): 2003-2016.

Varian, H. 1984. The Nonparametric Approach to Production Analysis. Econometrics. 52: 579-597.

Vishandass, AK., Lal, RC., Singh, Jaspal and Sharma, Amod. 2014. Inefficiency of Maze cultivation in different AgroClimatic zones of Uttar Pradesh. International Journal of Agricultural and Statistical Sciences. 10(1): 131-138.

Vodyanov, VA. and Kukuruza, IS. 2000. Ways of improving farm economics and sustainable production of maize in Volgograd Oblast. Kasetsart University, Bangkok (Thailand). 6: 3-8.

\section{How to cite this article:}

Vishandass, A.K., R.C. Lal, Jaspal Singh and Amod Sharma. 2018. Inefficiency in Cultivation of Maize on Different Sized Farm in Uttar Pradesh, India. Int.J.Curr.Microbiol.App.Sci. 7(05): 635-647. doi: https://doi.org/10.20546/ijcmas.2018.705.078 